\title{
Evaluation of Nursing Homes Using a Novel PROMETHEE Method for Probabilistic Linguistic Term Sets
}

\author{
Peng Li iD and Zhiwei Xu \\ College of Economics and Management, Jiangsu University of Science and Technology, Zhenjiang, Jiangsu 212003, China \\ Correspondence should be addressed to Peng Li; jellyok@126.com
}

Received 2 April 2021; Revised 25 April 2021; Accepted 26 April 2021; Published 7 May 2021

Academic Editor: Zeshui Xu

Copyright (C) 2021 Peng Li and Zhiwei Xu. This is an open access article distributed under the Creative Commons Attribution License, which permits unrestricted use, distribution, and reproduction in any medium, provided the original work is properly cited.

\begin{abstract}
Aging has become a serious social problem in China. Traditional informal long-term care is hard to sustain because of the reduction in family size and elders' children migration to big cities. The institution offering services for the disabled elders has been a tendency. There exists a strange phenomenon: some nursing homes are difficult to enter for most disabled elders, while the other ones must search for elders to maintain operation. Therefore, for the evaluation of nursing homes, two problems should be considered: (1) selecting suitable nursing homes for disabled elders; (2) obtaining the key factors influencing the selection of elders and helping nursing homes improve their services based on the key factors. First, we propose a new DEMATEL (Decision-Making Trial and Evaluation Laboratory) method for PLTSs to solve the second problem. Then, we present a novel PROMETHEE (Preference Ranking Organization Methods for Enrichment Evaluations) method to rank the alternatives and make a sensitivity analysis for criteria. Finally, we illustrate our proposed methods to an evaluation problem in Zhenjiang City by a case study. Based on the case study, we can obtain that our proposed methods are effective and practicable.
\end{abstract}

\section{Introduction}

With the development of society and medical level, China is entering an aging society. By the end of 2019, there are more than 253 million old people aged 60 or over. The population of disabled elders is more than 40 million. With the reducing size of families and adult children moving to cities, many disabled elders live alone and lack long-term care [1]. Traditional informal long-term care may lead to some problems for disabled elders, such as psychological loneliness [2] and reduction in household income [3]. Therefore, it is necessary for disabled elders to seek long-term care from nursing homes [4]. There have been numerous nursing homes in every city. The service levels of different nursing homes are multifarious. On one hand, some nursing homes are very popular that most disabled elders must wait for several years to enter them. On the other hand, many nursing homes' occupancy rate is very low. To cope with the contradiction, there are two key problems that need to be solved. (1) How to help disabled elders choose suitable nursing homes? (2) What are the factors of concern for disabled elders and how to improve these factors? For the first problem, we can use a multiple criteria decision-making (MCDM) method to solve. With respect to the second one, in this paper, we use a Decision-Making Trial and Evaluation Laboratory (DEMATEL) method to obtain the key factors for evaluation system.

For MCDM problems, there have been a large number of researches. In many cases, decision-makers (DMs) usually use linguistic information [5] to express their viewpoints. There have been lots of studies for linguistic information $[6,7]$. To aggregate the information of different DMs easily, Pang et al. [8] proposed the definition of probabilistic linguistic term set (PLTS). Many studies for PLTSs have emerged from theory to application. As for aggregating rules for PLTSs, Pang et al. [8] first proposed the basic rules for PLTSs. Liao et al. [9] proposed some new operational rules based on disparity degrees. Li and Wei [10] put forward a series of new rules based on evidence theory. With regard to the application of PLTSs, Lin et al. [11] put forward a novel 
best worst method for PLTS and applied it to evaluate IoT platforms. Li et al. [12] proposed a new case-based reasoning method for PLTS and solved the evaluation of povertystricken families. Lin et al. [13] proposed some clustering algorithms for PLTSs. Lin et al. [13] proposed an ELECTREE method for PLTS. Lin et al. [14] proposed a new score function for PLTS and applied it to select children English educational organization.

DEMATEL method is an effective way to obtain the key factors influencing the evaluation system. Cause-effect interactions for different criteria (factors) can be obtained by processing a comprehensive direct influencing matrix. DEMATEL method has been expanded to different uncertain information, such as fuzzy numbers [15], grey numbers [16], hesitant fuzzy linguistic term set [17], and PLTS [18]. DEMATEL method has been applied to many research areas, such as supply chain management [19], new energy [20], and business ecosystem [21].

To solve the second key problem mentioned in the first paragraph, we will use the DEMATEL method to analyze the key factors influencing the choices of disabled elders. Because the evaluation information is expressed by PLTSs, we should extend the traditional DEMATEL method to probabilistic linguistic environment. Furthermore, in order to address the first key problem, we will propose a new PROMETHEE method to help disabled elders select suitable nursing homes for them. We choose the PROMETHEE method because it is easy to make a sensitivity analysis for criteria weights.

In this paper, we will propose a new DEMATEL method for PLTS to make an analysis of key factors influencing the evaluation system. Then, we will put forward a novel PROMETHEE method to rank the alternatives and make a sensitivity analysis for criteria. The main contributions and innovation points of this paper can be concluded as follows:

(1) Propose a new DEMATEL method for PLTSs by transforming PLTSs into TFNs based on WOWA operators, which will help nursing homes obtain the concern factors of elders and can improve their services precisely
(2) Propose a novel PROMETHEE II method for PLTSs, which will help elders select the most suitable nursing homes

(3) Propose an approach to sensitivity analysis of criteria weights using a stability interval (WSI) method for PLTSs, which can help DMs find the variation range of criteria weights if the ranking results are stable

This paper is organized as follows. Section 2 reviews some basic definitions of PLTSs, TFNs, and WOWA operator. Section 3 proposes a novel DEMATEL method for PLTSs to obtain key factors for the evaluation system. Section 4 presents a PROMETHEE II method for PLTS and makes a sensitivity analysis for criteria. Section 5 applies our methods to an evaluation problem for nursing homes in Zhenjiang City. Section 6 makes a summary for this paper.

\section{Preliminaries}

In this section, we will review the basic definitions for PLTSs, TFNs, and WOWA operator.

2.1. PLTS. In real life, DMs may use linguistic information, such as "high" and "low," to express their opinions for evaluating some objects. A typical linguistic term set (LTS) can be described as $S=\left\{s_{t} \mid t=-\tau, \ldots,-1,0,1, \ldots, \tau\right\}$, where $\tau$ is a positive integer and $2 \tau+1$ is called granularity of LTS $S$.

It is easy to find that LTS can describe the subjectivity of DM. However, in many cases, there are many DMs participating in the decision process. Traditional LTS cannot express the information conveniently in this situation. To address this issue, Pang et al. [8] proposed the definition of PLTS, which can effectively describe the information of many DMs using LTSs.

Definition 1 (see [8]). Let $S$ be an LTS; then a PLTS can be defined as

$$
L(p)=\left\{L^{(k)}\left(p^{(k)}\right) \mid L^{(k)} \in S, \quad p^{(k)} \geq 0, k=1,2, \ldots, \# L(p), \sum_{k=1}^{\# L(p)} p^{(k)} \leq 1\right\}
$$

where $L^{(k)}\left(p^{(k)}\right)$ is the linguistic term $L^{(k)}$ associated with probability $p^{(k)}$ and $\# L(p)$ is the number of all different linguistic terms in $L(p)$.

Example 1. Given an LTS $S=\left\{s_{-2}, s_{-1}, s_{0}, s_{1}, s_{2}\right\}$, then $L_{1}(p)=\left\{s_{-1}(0.4), s_{0}(0.4), s_{1}(0.2)\right\}$ and $L_{1}(p)=\left\{s_{-1}(0.4)\right.$, $\left.s_{1}(0.4)\right\}$ are both PLTSs.

From Example 1, we can give some explanations: (1) for PLTS $L_{1}(p), 40$ percent of the DMs give evaluations using $s_{-1}, 40$ percent give of the DMs give evaluations using $s_{0}$, and 20 percent of the DMs give evaluations using $s_{1}$; (2) for PLTS
$L_{2}(p), 40$ percent of the DMs give evaluations using $s_{-1}, 40$ percent of the DMs give evaluations using $s_{1}$, and 20 percent of the DMs give up their opinions for some reasons. We can find that PLTSs can effectively describe the linguistic information of many DMs.

2.2. Triangular Fuzzy Number (TFN). TFN uses three elements to describe uncertain information. It is convenient to use TFNs to express some uncertain linguistic information [12]. The definition of TFN can be seen as in Definition 2. 
Definition 2 (see [22]). A three tuple $A=(a, b, c)$ is defined as a TFN if it satisfies

$$
\mu_{A}(x)= \begin{cases}0, & x<a, \\ \frac{x-a}{b-a}, & a \leq x \leq b, \\ \frac{c-x}{c-b}, & b \leq x \leq c, \\ 0, & x>c .\end{cases}
$$

Given three TFNs $A=(a, b, c), A_{1}=\left(a_{1}, b_{1}, c_{1}\right)$, and $A_{2}=\left(a_{2}, b_{2}, c_{2}\right)$, then the following operational rules hold [22]:

(1) $A_{1} \oplus A_{2}=\left(a_{1}+a_{2}, b_{1}+b_{2}, c_{1}+c_{2}\right)$

(2) $A_{1} \Theta A_{2}=\left(a_{1}-c_{2}, b_{1}-b_{2}, c_{1}-a_{2}\right)$

(3) $\eta A=(\eta a, \eta b, \eta c), \eta \geq 0$

Definition 3 (see $[18,22]$ ). Let $A=(a, b, c)$ be a TFN; then its defuzzified centroid can be defined as

$$
\operatorname{DC}(A)=\frac{a+b+c}{3} \text {. }
$$

2.3. WOWA Operator. The definition of the WOWA operator is defined as follows.

Definition 4 (see [23]). Let $P=\left(p_{1}, p_{2}, \ldots, p_{n}\right)$ be a weighting vector of numbers $a_{1}, a_{2}, \ldots, a_{n}$ satisfying $0 \leq p_{i} \leq 1$ and $\sum_{i=1}^{n} p_{i}=1$. Then, mapping $f_{\text {WOWA }}^{P, W}: R \longrightarrow R$, which has an associated weighting vector $W=\left(w_{1}\right.$, $\left.w_{2}, \ldots, w_{n}\right)$ such that $0 \leq w_{i} \leq 1$ and $\sum_{i=1}^{n} w_{i}=1$, is called a WOWA operator if

$$
f_{\text {WOWA }}^{P, W}\left(a_{1}, a_{2}, \ldots, a_{n}\right)=\sum_{i=1}^{n} v_{i} b_{i},
$$

where $b_{i}$ is the i-th largest element in $a_{1}, a_{2}, \ldots, a_{n}$ and $v_{i}$ is called comprehensive weight and can be obtained by

$$
v_{i}=w^{*}\left(\sum_{j=1}^{i} p_{\sigma(j)}\right)-w^{*}\left(\sum_{j=1}^{i-1} p_{\sigma(j)}\right),
$$

where $w^{*}$ is monotone increasing function and can be seen in the paper proposed by $\mathrm{Li}$ et al. [18].

For simplicity, we call $P=\left(p_{1}, p_{2}, \ldots, p_{n}\right)$ and $W=\left(w_{1}, w_{2}, \ldots, w_{n}\right)$ importance weighting vector and position weighting vector, respectively. We can obtain the position weighting vector $W=\left(w_{1}, w_{2}, \ldots, w_{n}\right)$ by the following mathematical programming [24]:

$$
\begin{aligned}
& \min \delta=\delta^{*}, \\
& (P 1) \text { s.t. }\left\{\begin{array}{l}
\operatorname{orness}\left(w^{*}\right)=\sum_{n=1}^{k} \frac{k-n}{k-1} \cdot w_{n}^{*}=\lambda, \\
\left|w_{n-1}^{*}-w_{n}^{*}\right| \leq \delta^{*}, \\
\sum_{n=1}^{k} w_{n}^{*}=1, \forall w_{n}^{*} \geq 0,
\end{array}\right.
\end{aligned}
$$

where parameter $\lambda$ can be given by DMs.

\section{Obtaining Key Factors for Evaluation System by DEMATEL Method for PLTSs}

When evaluating nursing homes, ranking alternatives are important but not the only target. Obtaining the key factors for the evaluation system is another target because it can help DMs to find the reasons leading to the decision results. DEMATEL method is an effective method to seek key factors and obtain criteria weights [18]. In the traditional DEMATEL method, DMs need to make a comparison between two criteria and give a comprehensive direct influencing matrix and then a total influencing matrix. The information for PLTSs cannot be used directly in the DEMATEL method. Therefore, we need to transform PLTSs into TFNs.
Given a PLTS $L(p)$, we can use the WOWA method to transform it into a TFN. We assume that a PLTS is $L(p)=\left\{s_{i}\left(p_{i}\right), s_{i+1}\left(p_{i+1}\right), \ldots, s_{j}\left(p_{j}\right)\right\}$. It is worth noting that, in traditional PLTS, the subscripts of linguistic terms may be not continuous. We need to add the missing linguistic terms with their probabilities equal to 0 . We can transform the linguistic term $s_{k}(i \leq k \leq j)$ into TFN $A_{k}=$ $\left(a_{k}^{L}, a_{k}^{M}, a_{k}^{R}\right)$ by the following rules $[18,25]$ :

(1) If $-\tau<k<\tau, \quad$ then $a_{k}^{L}=(\tau+k-1 / 2 \tau)$, $a_{k}^{M}=(\tau+k / 2 \tau)$, and $a_{k}^{R}=(\tau+k+1 / 2 \tau)$

(2) If $k=\tau$, then $a_{k}^{L}=(2 \tau-1 / 2 \tau)$ and $a_{k}^{M}=a_{k}^{R}=1$

(3) If $k=-\tau$, then $a_{k}^{L}=a_{k}^{M}=0$ and $a_{k}^{R}=(1 / 2 \tau)$

We can write $L(p)=\left\{s_{i}\left(p_{i}\right), s_{i+1}\left(p_{i+1}\right), \ldots, s_{j}\left(p_{j}\right)\right\}$ as a numerical set $T=\left\{a_{i}^{L}, a_{i}^{M}, a_{i+1}^{M}, \ldots, a_{j}^{M}, a_{j}^{R}\right\}$. Then, we can 
transform PLTS $L(p)$ into a TFN based on the following rules [18]:

$$
\begin{aligned}
& \text { Rule } 1: \text { if } j=\tau \text {, then TFN } A=\left(a_{i}^{L}, f_{\text {WOWA }}^{P, W}\right. \\
& \left.\left(a_{i}^{M}, a_{i+1}^{M}, \ldots, a_{\tau}^{M}\right), a_{\tau}^{M}\right) \\
& \text { Rule 2: if } i=-\tau \text {, then TFN } A=\left(a_{-\tau}^{M}, f_{\text {WOWA }}^{P, W}\right. \\
& \left.\left(a_{-\tau}^{M}, a_{-\tau+1}^{M}, \ldots, a_{j}^{M}\right), a_{j}^{R}\right) \\
& \text { Rule 3: If } i>-\tau \text { and } j<\tau \text {, then } A=\left(a_{i}^{L}, f_{\text {WOWA }}^{P, W}\right. \\
& \left.\left(a_{i}^{M}, a_{i+1}^{M}, \ldots, a_{j}^{M}\right), a_{j}^{R}\right)
\end{aligned}
$$

Based on Rules 1-3, PLTS $L(p)$ can be transformed into a TFN $A$. We then obtain key factors for evaluation system by the DEMATEL method as follows.

3.1. Establish a Comprehensive Direct Influencing Matrix Q. For the evaluation problem, experts $E_{1}, E_{2}, \ldots, E_{m}$ express their opinions by making pair comparisons for criteria $C_{1}, C_{2}, \ldots, C_{n}$ using LTS $S$. We aggregate the information from these experts and obtain a comprehensive direct influencing matrix $Q=\left(L_{i j}(p)\right)_{n \times n}$.

3.2. Transform the Matrix $Q$ into TFN Matrix A. Because we cannot illustrate PLTS matrix $Q$ to process the DEMATEL method, so we transform matrix $Q$ into TFN matrix $A=$ $\left(a_{i j}^{L}, a_{i j}^{M}, a_{i j}^{R}\right)_{n \times n}$ based on Rules $1-3$.

3.3. Obtain Total Influencing Matrix T. Normalize TFN matrix $A$ to $B=\left(b_{i j}^{L}, b_{i j}^{M}, b_{i j}^{R}\right)_{n \times n}=\left(\left(a_{i j}^{L} / \rho\right),\left(a_{i j}^{M} / \rho\right),\left(a_{i j}^{R} /\right.\right.$ $\rho))_{n \times n}$, where $\rho=\max \left\{\max _{i}\left\{\sum_{j} a_{i j}^{R}\right\}, \max _{j}\left\{\sum_{i} a_{i j}^{R}\right\}\right\}$. Compute the total influencing matrix $T$ based on

$$
T=\left(t_{i j}^{L}, t_{i j}^{M}, t_{i j}^{R}\right)_{n \times n}=B+B^{2}+\cdots=B(I-B)^{-1} .
$$

3.4. Make an Analysis for Relationship of Criteria. Based on total influencing matrix $T$, compute the defuzzified centroid matrix $Y=\left(y_{i j}\right)_{n \times n}=\left(t_{i j}^{L}+t_{i j}^{M}+t_{i j}^{R} / 3\right)_{n \times n}$. Calculate sums of rows and columns of matrix $Y$ as follows:

$$
\begin{aligned}
r_{i} & =\sum_{j=1}^{n} y_{i j}, \\
c_{i} & =\sum_{i=1}^{n} y_{i j} .
\end{aligned}
$$

Set a threshold $\varepsilon=\left(\sum_{i}^{n} \sum_{j}^{n} y_{i j} / n^{2}\right)$ [26]. In the defuzzified centroid matrix $Y$, if the element $y_{i j}>\varepsilon$, we can say criterion $C_{i}$ has influence on $C_{j}$.

Make an analysis based on the values of $r_{i}-c_{i}$, which indicates net effect of criterion $C_{i}$ to the evaluation system. If $r_{i}-c_{i}>0$, then criterion $C_{i}$ is called net cause factor. On the contrary, if $r_{i}-c_{i}<0$, then criterion $C_{i}$ is called result factor.

Furthermore, we can obtain the criteria weights by the following [27]:

$$
\omega_{i}=\frac{\sqrt{2\left(r_{i}\right)^{2}+2\left(c_{i}\right)^{2}}}{\sum_{i=1}^{n} \sqrt{2\left(r_{i}\right)^{2}+2\left(c_{i}\right)^{2}}} .
$$

\section{A Novel PROMETHEE II Method for PLTS and Sensitivity Analysis for Criteria}

In this section, we will propose a novel PROMETHEE II method for PLTS and make a sensitivity analysis for criteria based on the WSI method.

4.1. A PROMETHEE II Method for PLTS. For evaluating nursing homes problems, criterion set is $C=\left(C_{1}, C_{2}, \ldots, C_{n}\right)$, alternative set (nursing homes) is $X=\left\{X_{1}, X_{2}, \ldots, X_{m}\right\}$, and the criteria weights set is $W=\left(\omega_{1}, \omega_{2}, \ldots, \omega_{n}\right)$. Experts give a decision matrix $U=\left(u_{i j}\right)_{m \times n}$, where $u_{i j}$ is a PLTS and indicates the value alternative $X_{i}$ with respect to criterion $C_{j}$.

Step 1. Transform PLTS matrix $U$ into TFN information

To make the decision process easy to compute, we firstly transform PLTS matrix $U$ into TFN matrix $H=$ $\left(h_{i j}^{L}, h_{i j}^{M}, h_{i j}^{R}\right)_{m \times n}$ based on Rules $1-3$ in Section 3.

Step 2. Obtain the defuzzified centroid matrix $Z$

Compute the defuzzified centroid matrix of TFN matrix $H$ as $Z=\left(z_{i j}\right)_{m \times n}$, where

$$
z_{i j}=\frac{h_{i j}^{L}+h_{i j}^{M}+h_{i j}^{R}}{3} .
$$

Step 3. Determine the positive flow $\Phi^{+}$and negative flow $\Phi^{-}$

For criterion $C_{j}$, the preference degree for alternative $X_{i}$ over $X_{k}$ can be obtained by

$$
F_{j}\left(X_{i}, X_{k}\right)=H_{j}\left(z_{i j}-z_{k j}\right) \text {, }
$$

where $H_{j}$ is a nondecreasing preference function. There are mainly six types of preference functions to choose [28]. In this paper, in order to compute simply, we choose the following preference function:

$$
H_{j}(x, y)= \begin{cases}1, & x \geq y \\ 0, & x<y .\end{cases}
$$

Then, we can obtain the overall preference value of alternative $X_{i}$ over $X_{k}$ as

$$
F\left(X_{i}, X_{k}\right)=\sum_{j=1}^{n} \omega_{j} F_{j}\left(X_{i}, X_{k}\right),
$$

where $\omega_{j}$ is the criterion weight for $C_{j}$ and can be obtained by equation (9). 
The positive flow $\Phi^{+}\left(X_{i}\right)$ and negative flow $\Phi^{-}\left(X_{i}\right)$ for alternative $X_{i}$ can be calculated by (14) and (15), respectively:

$$
\begin{aligned}
& \Phi^{+}\left(X_{i}\right)=\frac{1}{m-1} \sum_{k=1, k \neq i}^{m} F\left(X_{i}, X_{k}\right), \\
& \Phi^{-}\left(X_{i}\right)=\frac{1}{m-1} \sum_{k=1, k \neq i}^{m} F\left(X_{k}, X_{i}\right) .
\end{aligned}
$$

Step 4. Compute the net flow $\Phi$ and rank the alternatives

The net flow $\Phi\left(X_{i}\right)$ for alternative $X_{i}$ can be calculated by (16):

$$
\Phi\left(X_{i}\right)=\Phi^{+}\left(X_{i}\right)-\Phi^{-}\left(X_{i}\right)
$$

Rank the alternatives according to the values of net flow for all alternatives. The larger the values of net flow of the alternative, the higher the priority of the alternative.

4.2. Sensitivity Analysis for Criteria Using WSI Method. Accurate criteria weights are very important to make a reasonable decision. WSI method [29] is an effective method to make a sensitivity analysis for criteria. For criterion $C_{j}$, its weight is $\omega_{j}$, and we will see how the weight value can be modified without changing the ranking result. The new criteria weights are defined as follows:

$$
\begin{aligned}
& \omega_{j}^{\prime}=(1+\alpha) \cdot \omega_{j}, \alpha \geq-1, \\
& \omega_{l}^{\prime}=\beta \cdot \omega_{l}, \beta=\frac{1-(1+\alpha) \omega_{j}}{1-\omega_{j}}, 0 \leq \beta \leq \frac{1}{1-\omega_{j}}, \forall l \neq j .
\end{aligned}
$$

Based on the PROMETHEE II method, we assume that

$$
\begin{aligned}
\Delta\left(X_{i}, X_{k}\right) & =\Phi\left(X_{i}\right)-\Phi\left(X_{k}\right), \\
\Delta_{j}\left(X_{i}, X_{k}\right) & =\Phi_{j}\left(X_{i}\right)-\Phi_{j}\left(X_{k}\right)=\frac{1}{m-1}\left(\sum_{h=1, h \neq i}^{m} F_{j}\left(X_{i}, X_{h}\right)-\sum_{h=1, h \neq k}^{m} F_{j}\left(X_{k}, X_{h}\right)\right) .
\end{aligned}
$$

We give the following definition:

$$
\begin{aligned}
& \Omega^{0}=\left\{\left(X_{i}, X_{k}\right) \in X \times X, \text { s.t. } \Delta_{j}\left(X_{i}, X_{k}\right)<0 \text { and } \Delta\left(X_{i}, X_{k}\right)=0\right\}, \\
& \Omega^{-}=\left\{\left(X_{i}, X_{k}\right) \in X \times X \text {, s.t. } \Delta\left(X_{i}, X_{k}\right) \cdot \Delta_{j}\left(X_{i}, X_{k}\right)<0\right\}, \\
& \Omega^{+}=\left\{\left(X_{i}, X_{k}\right) \in X \times X \text {, s.t. } \Delta\left(X_{i}, X_{k}\right) \cdot \Delta_{j}\left(X_{i}, X_{k}\right)>\Delta^{2}\left(X_{i}, X_{k}\right)\right\}, \\
& \beta_{j}^{-}=\max \frac{\Delta\left(X_{i}, X_{k}\right) \cdot \Delta_{j}\left(X_{i}, X_{k}\right)}{\Delta\left(X_{i}, X_{k}\right) \cdot \Delta_{j}\left(X_{i}, X_{k}\right)-\Delta^{2}\left(X_{i}, X_{k}\right)}, \quad\left(X_{i}, X_{k}\right) \in \Omega^{-}, \\
& \beta_{j}^{+}=\min \frac{\Delta\left(X_{i}, X_{k}\right) \cdot \Delta_{j}\left(X_{i}, X_{k}\right)}{\Delta\left(X_{i}, X_{k}\right) \cdot \Delta_{j}\left(X_{i}, X_{k}\right)-\Delta^{2}\left(X_{i}, X_{k}\right)}, \quad\left(X_{i}, X_{k}\right) \in \Omega^{+} .
\end{aligned}
$$

Then, we can get the weight stability interval of the criterion $C_{j}$ as follows:

$$
\left(\omega_{j}^{-}, \omega_{j}^{+}\right)=\left(1-\left(1-\omega_{j}\right) \cdot \beta_{j}^{+}, 1-\left(1-\omega_{j}\right) \cdot \beta_{j}^{-}\right),
$$

where $\omega_{j}^{-}$and $\omega_{j}^{+}$are the lower and upper bounds of the weight stable interval of criterion $C_{j}$.

\section{A Case Study}

In this section, we will use our proposed methods to solve the evaluation of nursing homes in Zhenjiang City, Jiangsu Province. This section will include four parts: (1) decision problem description, (2) obtaining key factors for evaluation system and criteria weights based on DEMATEL, (3) ranking alternatives based on PROMETHEE II method for PLTS, and (4) further discussions and sensitivity analysis using WSI method.

5.1. Decision Problem Description. In recent years, due to the influence of the fertility policy, the number of the elderly populations in China began to increase continuously. China has become an aging population country. In such a population environment, the pension service industry began to develop. There are a variety of different pension models for the elderly to choose. As part of the pension pattern, institutional pensions are defined as institutions that provide 
TABle 1: Comprehensive direct influencing matrix $Q$.

\begin{tabular}{ccccc}
\hline & $C_{1}$ & $C_{2}$ & $C_{3}$ & $C_{4}$ \\
\hline$C_{1}$ & 0 & $\left\{s_{-2}(0.2), s_{-1}(0.2), s_{1}(0.4), s_{2}(0.2)\right\}$ & $\left\{s_{-2}(0.2), s_{-1}(0.5), s_{2}(0.3)\right\}$ & $\left\{s_{-2}(0.3), s_{-1}(0.3), s_{0}(0.4)\right\}$ \\
$C_{2}$ & $\left\{s_{-2}(0.2), s_{-1}(0.3), s_{0}(0.5)\right\}$ & 0 & $\left\{s_{-2}(0.2), S_{1}(0.6), s_{2}(0.2)\right\}$ & $\left\{s_{-1}(0.2), S_{1}(0.6), s_{2}(0.2)\right\}$ \\
$C_{3}$ & $\left\{s_{-1}(0.3), s_{0}(0.2), s_{1}(0.2), s_{2}(0.3)\right\}$ & $\left\{s_{0}(0.4), s_{1}(0.2), S_{2}(0.4)\right\}$ & 0 & $\left\{s_{-2}(0.2), s_{-1}(0.6), s_{2}(0.2)\right\}$ \\
$C_{4}$ & $\left\{s_{-2}(0.3), s_{-1}(0.1), s_{0}(0.6)\right\}$ & $\left\{s_{0}(0.5), s_{1}(0.3), s_{2}(0.2)\right\}$ & $\left\{s_{0}(0.3), s_{1}(0.6), s_{2}(0.1)\right\}$ & 0
\end{tabular}

TABle 2: TFN matrix $A$.

\begin{tabular}{ccccc}
\hline & $C_{1}$ & $C_{2}$ & $C_{3}$ & $C_{4}$ \\
\hline$C_{1}$ & $<0.000,0.000,0.000>$ & $<0.000,0.620,1.000>$ & $<0.000,0.775,1.000>$ & $<0.000,0.225,0.750>$ \\
$C_{2}$ & $<0.000,0.282,0.750>$ & $<0.000,0.000,0.000>$ & $<0.000,0.800,1.000>$ & $<0.000,0.805,1.000>$ \\
$C_{3}$ & $<0.000,0.606,1.000>$ & $<0.250,0.757,1.000>$ & $<0.000,0.000,0.000>$ & $<0.000,0.800,1.000>$ \\
$C_{4}$ & $<0.000,0.339,0.750>$ & $<0.250,0.782,1.000>$ & $<0.250,0.804,1.000>$ & $<0.000,0.000,0.000>$ \\
\hline
\end{tabular}

TABLE 3: Total influencing matrix $T$.

\begin{tabular}{ccccc}
\hline & $C_{1}$ & $C_{2}$ & $C_{3}$ & $C_{4}$ \\
\hline$C_{1}$ & $<0.000,0.191,3.267>$ & $<0.000,0.472,4.000>$ & $<0.000,0.529,4.000>$ & $<0.000,0.357,3.733>$ \\
$C_{2}$ & $<0.000,0.306,3.467>$ & $<0.000,0.351,3.750>$ & $<0.000,0.583,4.000>$ & $<0.000,0.540,3.783>$ \\
$C_{3}$ & $<0.000,0.403,3.733>$ & $<0.083,0.585,4.250>$ & $<0.000,0.411,4.000>$ & $<0.000,0.563,4.017>$ \\
$C_{4}$ & $<0.000,0.322,3.467>$ & $<0.090,0.562,4.000>$ & $<0.083,0.589,4.000>$ & $<0.000,0.332,3.533>$ \\
\hline
\end{tabular}

Table 4: Defuzzified centroid matrix $Y$.

\begin{tabular}{lcccc}
\hline & $C_{1}$ & $C_{2}$ & $C_{3}$ & $C_{4}$ \\
\hline$C_{1}$ & 1.153 & $\mathbf{1 . 4 9 1}$ & $\mathbf{1 . 5 1 0}$ & 1.363 \\
$C_{2}$ & 1.257 & 1.367 & $\mathbf{1 . 5 2 8}$ & $\mathbf{1 . 4 4 1}$ \\
$C_{3}$ & 1.379 & $\mathbf{1 . 6 4 0}$ & 1.470 & $\mathbf{1 . 5 2 7}$ \\
$C_{4}$ & 1.263 & $\mathbf{1 . 5 5 1}$ & $\mathbf{1 . 5 5 8}$ & 1.288 \\
\hline
\end{tabular}

centralized housing and care services for the elderly, such as nursing homes.

Recently, we walked into a service community for the elderly in Zhenjiang City, Jiangsu Province. In the early stage of preparation, we collected the relevant information of caregivers in four local nursing homes. In the process of investigation, we provided the relevant materials of caregivers in four nursing homes to the elderly in the community and invited them to make a comprehensive evaluation of caregivers in four nursing homes $\left(X_{1}, X_{2}, X_{3}, X_{4}\right)$. There are four criteria [30] considered in the evaluation process: price acceptability $\left(C_{1}\right)$, sustainability of service $\left(C_{2}\right)$, responsibility $\left(C_{3}\right)$, and service quality $\left(C_{4}\right)$.

\subsection{Obtaining Key Factors for Evaluation System and Criteria Weights Based on DEMATEL.}

(1) We invite ten experts to make a comparison between two criteria using LTSs. By aggregating the information, we obtain the comprehensive direct influencing matrix $Q$ as shown in Table 1.

(2) Based on Rules 1-3, we obtain the TFN matrix $A$ as shown in Table 2.

(3) Based on equation (6), we obtain the total influencing matrix $T$ as shown in Table 3.
(4) We can compute the defuzzified centroid matrix $Y$ as shown in Table 4.

We can obtain the threshold $\varepsilon=\left(\sum_{i}^{n} \sum_{j}^{n} y_{i j} / n^{2}\right)=1.424$. Influence relation between criteria can be seen in Figure 1 .

The values of $r_{i} c_{i}, r_{i}+c_{i}, r_{i}-c_{i}$ and $\omega_{j}$ can be seen in Table 5.

We can obtain the cause-effect relationship of criteria as shown in Figure 2.

It can be seen from Figure 2 that criteria price acceptability $\left(C_{1}\right)$ and service quality $\left(C_{4}\right)$ are cause factors influencing the evaluation system, while and sustainability of service $\left(C_{2}\right)$ and responsibility $\left(C_{3}\right)$ are effect ones that are affected by the evaluation system. In other words, price acceptability $\left(C_{1}\right)$ and service quality $\left(C_{4}\right)$ are the most concerned factors of elders in four ones. Nursing homes should lower the service price and improve service quality.

5.3. Ranking Alternatives Based on PROMETHEE II Method for PLTS. Based on the aggregation of the experts' opinions, the decision matrix $U$ can be seen in Table 6 .

Step 1. Based on Rules 1-3, we can transform PLTS matrix $U$ into TFN decision matrix $H$ as shown in Table 7 . 


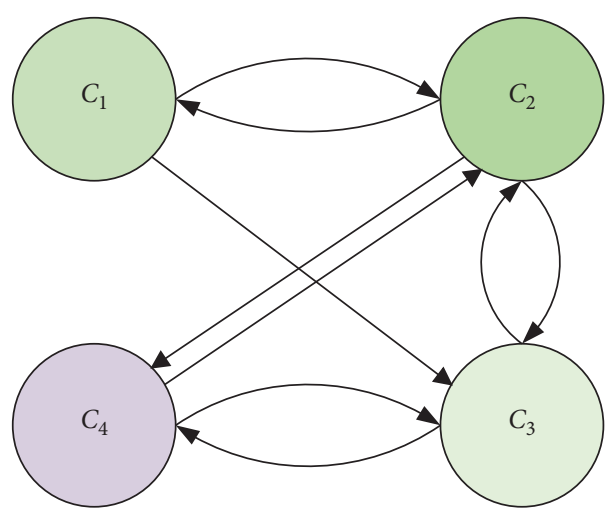

FIGURE 1: Influence relation diagram between criteria.

TABLE 5: Values of $r_{i} c_{i}, r_{i}+c_{i}, r_{i}-c_{i}$, and $\omega_{j}$.

\begin{tabular}{|c|c|c|c|c|c|}
\hline & $r_{i}$ & $c_{i}$ & $r_{i}+c_{i}$ & $r_{i}-c_{i}$ & $\omega_{j}$ \\
\hline$C_{1}$ & 5.516 & 5.052 & 10.568 & 0.464 & 0.232 \\
\hline$C_{2}$ & 5.593 & 6.048 & 11.641 & -0.454 & 0.255 \\
\hline$C_{3}$ & 6.015 & 6.065 & 12.080 & -0.050 & 0.265 \\
\hline$C_{4}$ & 5.659 & 5.620 & 11.279 & 0.040 & 0.248 \\
\hline
\end{tabular}

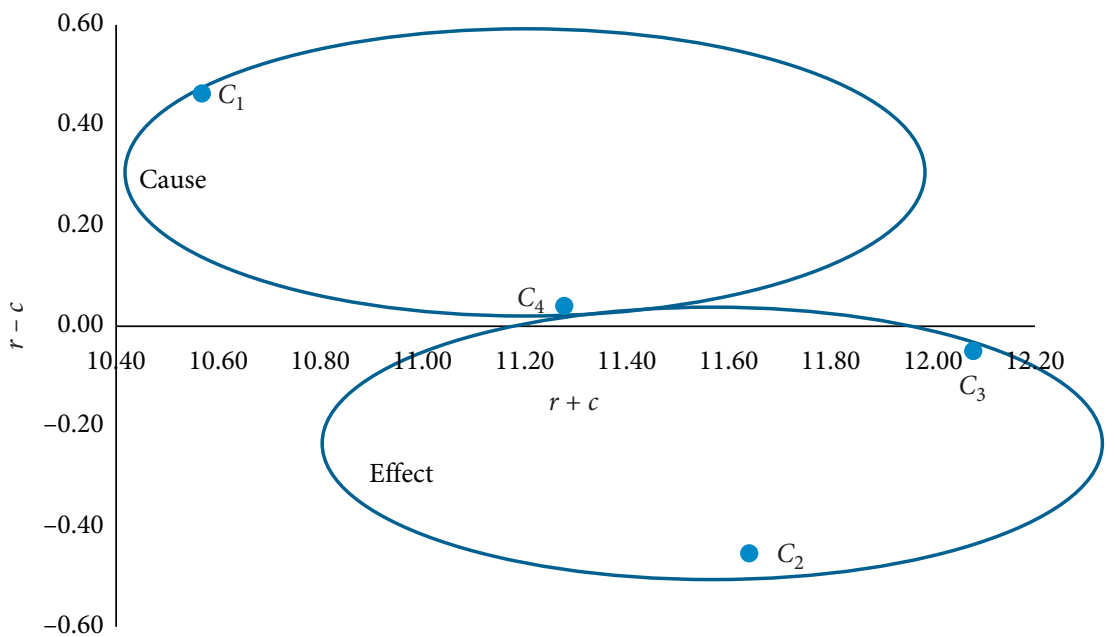

Figure 2: Cause-effect relationship of criteria.

TABLe 6: Decision matrix $U$.

\begin{tabular}{ccccc}
\hline & $C_{1}$ & $C_{2}$ & $C_{3}$ & $C_{4}$ \\
\hline$X_{1}$ & $\left\{s_{-1}(0.4), s_{0}(0.2), S_{1}(0.4)\right\}$ & $\left\{s_{-1}(0.2), s_{1}(0.8)\right\}$ & $\left\{s_{-2}(0.6), s_{1}(0.4)\right\}$ & $\left\{s_{-2}(0.2), s_{-1}(0.4), s_{0}(0.2), s_{2}(0.2)\right\}$ \\
$X_{2}$ & $\left\{s_{-1}(0.2), s_{0}(0.4), s_{1}(0.2), s_{2}(0.2)\right\}$ & $\left\{s_{-1}(0.4), S_{1}(0.4), s_{2}(0.2)\right\}$ & $\left\{s_{-2}(0.2), s_{-1}(0.6), s_{0}(0.2)\right\}$ & $\left\{s_{-1}(0.4), s_{1}(0.6)\right\}$ \\
$X_{3}$ & $\left\{s_{-2}(0.3), s_{-1}(0.3), s_{0}(0.4)\right\}$ & $\left\{s_{-1}(0.4), s_{0}(0.2), s_{1}(0.2), s_{2}(0.2)\right\}$ & $\left\{s_{-1}(0.2), s_{0}(0.3), s_{1}(0.4), s_{2}(0.1)\right\}$ & $\left\{s_{-2}(0.4), s_{0}(0.6)\right\}$ \\
$X_{4}$ & $\left\{s_{-1}(0.3), s_{1}(0.5), s_{2}(0.2)\right\}$ & $\left\{s_{0}(0.4), s_{1}(0.4), s_{2}(0.2)\right\}$ & $\left\{s_{-1}(0.2), s_{0}(0.2), s_{1}(0.4), s_{2}(0.2)\right\}$ & $\left\{s_{0}(0.2), s_{1}(0.6), s_{2}(0.2)\right\}$ \\
\hline
\end{tabular}

TABLe 7: TFN decision matrix $H$.

\begin{tabular}{ccccc}
\hline & $C_{1}$ & $C_{2}$ & $C_{3}$ & $C_{4}$ \\
\hline$X_{1}$ & $<0.000,0.507,1.000>$ & $<0.000,0.683,1.000>$ & $<0.000,0.623,1.000>$ & $<0.000,0.620,1.000>$ \\
$X_{2}$ & $<0.000,0.628,1.000>$ & $<0.000,0.755,1.000>$ & $<0.000,0.307,0.750>$ & $<0.000,0.624,1.000>$ \\
$X_{3}$ & $<0.000,0.225,0.750>$ & $<0.000,0.628,1.000>$ & $<0.000,0.690,1.000>$ & $<0.000,0.372,0.750>$ \\
$X_{4}$ & $<0.000,0.777,1.000>$ & $<0.250,0.757,1.000>$ & $<0.000,0.628,1.000>$ & $<0.250,0.807,1.000>$ \\
\hline
\end{tabular}


Table 8: Defuzzified centroid matrix $Z$.

\begin{tabular}{lcccr}
\hline & $C_{1}$ & $C_{2}$ & $C_{3}$ & $C_{4}$ \\
\hline$X_{1}$ & 0.502 & 0.561 & 0.541 & 0.540 \\
$X_{2}$ & 0.543 & 0.585 & 0.352 & 0.541 \\
$X_{3}$ & 0.325 & 0.543 & 0.563 & 0.374 \\
$X_{4}$ & 0.592 & 0.669 & 0.543 & 0.686 \\
\hline
\end{tabular}

TABLe 9: Values of positive flow $\Phi^{+}$.

\begin{tabular}{lcccc}
\hline & $C_{1}$ & $C_{2}$ & $C_{3}$ & \\
\hline$X_{1}$ & 1 & 1 & 1 & \\
$X_{2}$ & 2 & 2 & 0 & \\
$X_{3}$ & 0 & 0 & 3 & 2 \\
$X_{4}$ & 3 & 3 & 2 & 0 \\
\hline
\end{tabular}

TABLe 10: Values of negative flow $\Phi^{-}$.

\begin{tabular}{lcccc}
\hline & $C_{1}$ & $C_{2}$ & $C_{3}$ & \\
\hline$X_{1}$ & 2 & 2 & 2 & \\
$X_{2}$ & 1 & 1 & 3 & \\
$X_{3}$ & 3 & 3 & 0 & 1 \\
$X_{4}$ & 0 & 0 & 1 & 3 \\
\hline
\end{tabular}

TABle 11: Comparison results with the method of Pang et al. [8].

\begin{tabular}{lcc}
\hline Decision-making method & Ranking order & Optimal alternative \\
\hline Pang et al. [8] method & $X_{4}>X_{1}>X_{2}>X_{3}$ & $X_{4}$ \\
Proposed method & $X_{4}>X_{2}>X_{1}>X_{3}$ & $X_{4}$ \\
\hline
\end{tabular}

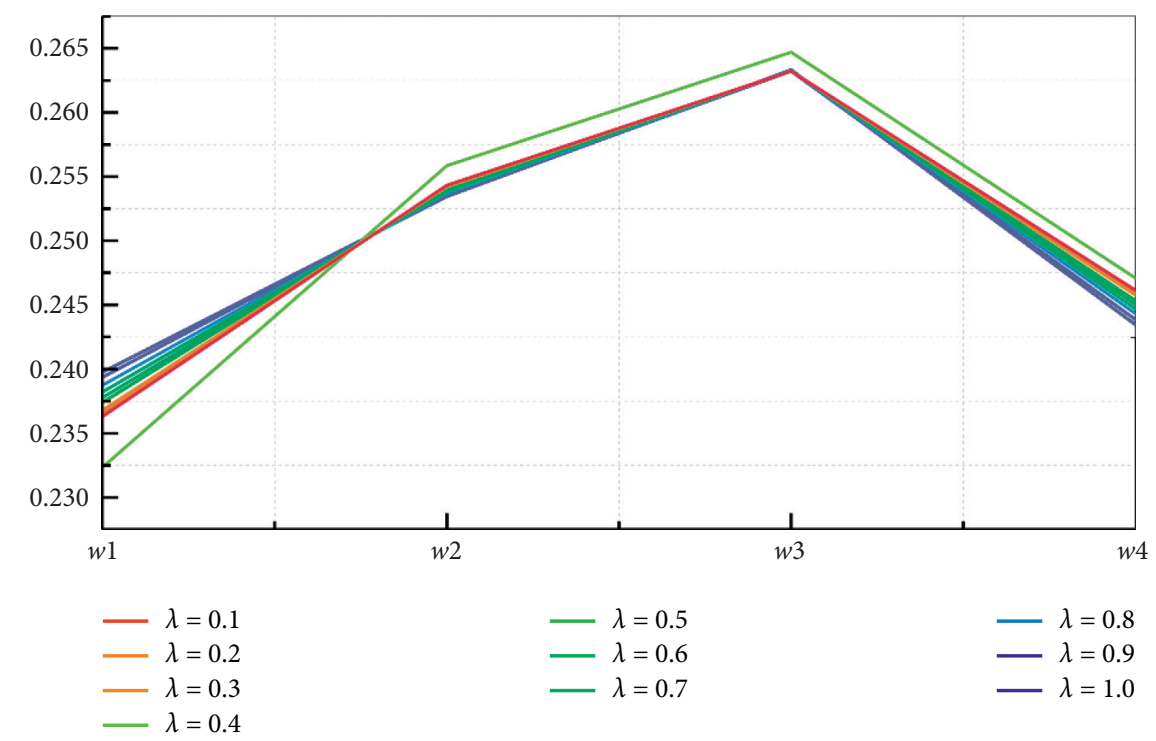

Figure 3: Values of criteria weights under different parameter $\lambda$. 
TABle 12: Ranking results under different parameter $\lambda$.

\begin{tabular}{lcc}
\hline$\lambda$ & Ranking order & Optimal alternative \\
\hline 0.1 & $X_{4}>X_{1}>X_{2}>X_{3}$ & $X_{4}$ \\
0.2 & $X_{4}>X_{2}>X_{1}>X_{3}$ & $X_{4}$ \\
0.3 & $X_{4}>X_{2}>X_{1}>X_{3}$ & $X_{4}$ \\
0.4 & $X_{4}>X_{2}>X_{1}>X_{3}$ & $X_{4}$ \\
0.5 & $X_{4}>X_{2}>X_{3}>X_{1}$ & $X_{4}$ \\
0.6 & $X_{4}>X_{2}>X_{3}>X_{1}$ & $X_{4}$ \\
0.7 & $X_{4}>X_{2}>X_{3}>X_{1}$ & $X_{4}$ \\
0.8 & $X_{4}>X_{2}>X_{3}>X_{1}$ & $X_{4}$ \\
0.9 & $X_{4}>X_{2}>X_{3}>X_{1}$ & $X_{4}$ \\
1.0 & $X_{4}>X_{2}>X_{3}>X_{1}$ & $X_{4}$ \\
\hline
\end{tabular}

TABLE 13: Results of stable weight intervals using the WSI method.

\begin{tabular}{lcccc}
\hline$\lambda=0.1$ & $C_{1}$ & $C_{2}$ & $C_{3}$ & $C_{4}$ \\
\hline$\left(\beta_{j}^{-}, \beta_{j}^{+}\right)$ & $(0.000,1.308)$ & $(0.000,1.340)$ & $(0.777,1.357)$ & $(0.556,1.326)$ \\
$\left(\omega_{j}^{-}, \omega_{j}^{+}\right)$ & $(0.000,1.000)$ & $(0.000,1.000)$ & $(0.000,0.428)$ & $(0.000,0.581)$ \\
$\lambda=0.4$ & $C_{1}$ & $C 2$ & $C 3$ & $(0.907,1.361)$ \\
$\left(\beta_{j}^{-}, \beta_{j}^{+}\right)$ & $(0.000,1.258)$ & $(0.000,1.258)$ & $(0.000,1.258)$ \\
$\left(\omega_{j}^{-}, \omega_{j}^{+}\right)$ & $(0.034,1.000)$ & $(0.063,1.000)$ & $(0.000,0.333)$ & $C_{3}$ \\
$\lambda=0.7$ & $C_{1}$ & $C_{2}$ & $(0.808,1.027)$ & $(0.974,1.325)$ \\
$\left(\beta_{j}^{-}, \beta_{j}^{+}\right)$ & $(0.949,1.312)$ & $(0.000,1.056)$ & $(0.243,0.405)$ & $(0.000,0.264)$ \\
$\left(\omega_{j}^{-}, \omega_{j}^{+}\right)$ & $(0.001,0.276)$ & $(0.212,1.000)$ & \\
\hline
\end{tabular}

Step 2. We can obtain the defuzzified centroid matrix $Z$ as shown in Table 8.

Step 3. Obtain the positive flow $\Phi^{+}$and negative flow $\Phi^{-}$as shown in Tables 9 and 10, respectively.

Step 4. Compute the net flow $\Phi$ of four alternatives as follows:

$$
\begin{aligned}
& \Phi\left(X_{1}\right)=-0.333, \\
& \Phi\left(X_{2}\right)=-0.020, \\
& \Phi\left(X_{3}\right)=-0.470, \\
& \Phi\left(X_{4}\right)=0.823 .
\end{aligned}
$$

The ranking result is $X_{4}>X_{2}>X_{1}>X_{3}$.

We make a comparison between our proposed method and the method proposed by Pang et al. [8] as shown in Table 11.

As can be seen from Table 11, the ranking results of the two methods are different. The main reason may be lie in the different decision-making mechanisms for the two methods. The method proposed by Pang et al. [8] uses the traditional TOPSIS method, while our method uses a specific outranking method. The advantages of the method to the other one are simple calculation and convenience in sensitivity analysis using the WSI method.

5.4. Further Discussions and Sensitivity Analysis Using WSI Method. In Section 3, the values parameter $\lambda$ can make an influence on the final decision results. We will choose different values of $\lambda$ to discuss the ranking results and sensitivity analysis situations. The criteria weights and ranking results under different values of $\lambda$ can be seen in Figure 3 and Table 12 , respectively.

We choose $\lambda=0.1, \lambda=0.4$, and $\lambda=0.7$ to make a sensitivity analysis using the WSI method as shown in Table 13.

As can be seen from Table 13, the smaller the value of parameter $\lambda$, the larger stable the weight intervals. In fact, the parameter can reflect the confidences of DMs. If DMs have enough confidence on their judgments, the variation of weights will be very small. This is also true of reality.

\section{Conclusions}

China has been one of the most serious aging countries in the world. With the liberalization of the family planning policy, more and more families have two children. Many families have the 4-2-2 family structure, which means a couple should support four elders and raise two children. It is difficult for the couple to spend enough time to support the four elders. Furthermore, many young people migrate to big cities to bring home the bacon. Traditional informal preserving pattern for the elders based on families is not realizable for many families. The institution offering services for the elders is a new tendency. A few nursing homes' supply falls short of demand that leads to the fact that most elders cannot enjoy their care services. While most private nursing homes operate hardly and have to look for customers. In order to resolve the contradiction, it is necessary to evaluate nursing homes, which will not only help elders to select suitable nursing homes but also find key concern point for elders. Therefore, in this paper, the evaluation process has two phases: seeking key factors and ranking results. We illustrate the DEMATEL method for PLTSs to analyze the key factors influencing evaluation process and obtain criteria 
weights. Then, we propose a novel PROMETHEE method to rank the alternatives and make a sensitivity analysis for criteria. Finally, we applied our methods to solve the nursing homes evaluation problem in Zhenjiang City to illustrate the effectiveness and practicability of our methods.

Future research will focus on clustering disabled elders to different categories based on case-based reasoning method, which will help government to give different financial support for certain disabled elders [31].

\section{Data Availability}

No data were used to support this study.

\section{Conflicts of Interest}

The authors declare that there are no conflicts of interest regarding the publication of this paper.

\section{Acknowledgments}

This paper was supported by the Ministry of Education Foundation of Humanities and Social Sciences of China (no. 19YJA630039).

\section{References}

[1] M. Li and H. Dai, "Determining the primary caregiver for disabled older adults in Mainland China: spouse priority and living arrangements," Journal of Family Therapy, vol. 41, no. 1, pp. 126-141, 2019.

[2] N. B. Coe and C. H. Van Houtven, "Caring for mom and neglecting yourself? The health effects of caring for an elderly parent," Health Economics, vol. 18, no. 9, pp. 991-1010, 2009.

[3] A. Heitmueller, "The chicken or the egg?" Journal of Health Economics, vol. 26, no. 3, pp. 536-559, 2007.

[4] L. Arnault, J.-F. Dartigues, C. Helmer, K. Pérès, and J. Wittwer, "Do partners of severely disabled elderly protect against nursing home entry? evidence from a French cohort," The Journal of the Economics of Ageing, vol. 15, Article ID 100207, 2020.

[5] L. A. Zadeh, "The concept of a linguistic variable and its application to approximate reasoning-I," Information Sciences, vol. 8, no. 3, pp. 199-249, 1975.

[6] D. Pamučar, S. Sremac, Ž. Stević, G. Ćirović, and D. Tomić, "New multi-criteria LNN WASPAS model for evaluating the work of advisors in the transport of hazardous goods," Neural Computing and Applications, vol. 31, pp. 5045-5068, 2019.

[7] E. K. Zavadskas, R. Bausys, and I. Mazonaviciute, "Safety evaluation methodology of urban public parks by multi-criteria decision making," Landscape and Urban Planning, vol. 189, pp. 372-381, 2019.

[8] Q. Pang, H. Wang, and Z. Xu, "Probabilistic linguistic term sets in multi-attribute group decision making," Information Sciences, vol. 369, pp. 128-143, 2016.

[9] H. Liao, L. Jiang, B. Lev, and H. Fujita, "Novel operations of PLTSs based on the disparity degrees of linguistic terms and their use in designing the probabilistic linguistic ELECTRE III method," Applied Soft Computing, vol. 80, pp. 450-464, 2019.

[10] P. Li and C. Wei, "An emergency decision-making method based on D-S evidence theory for probabilistic linguistic term sets," International Journal of Disaster Risk Reduction, vol. 37, Article ID 101178, 2019.
[11] M. Lin, C. Huang, Z. Xu, and R. Chen, "Evaluating IoT platforms using integrated probabilistic linguistic MCDM method," IEEE Internet of Things Journal, vol. 7, no. 11, pp. 11195-11208, 2020.

[12] P. Li, J. Liu, Y. Yang, and C. Wei, "Evaluation of povertystricken families in rural areas using a novel case-based reasoning method for probabilistic linguistic term sets," Computers \& Industrial Engineering, vol. 147, Article ID 106658, 2020a.

[13] M. Lin, Z. Chen, H. Liao, and Z. Xu, "ELECTRE II method to deal with probabilistic linguistic term sets and its application to edge computing," Nonlinear Dynamics, vol. 96, no. 3, pp. 2125-2143, 2019.

[14] M. Lin, Z. Chen, Z. Xu, X. Gou, and F. Herrera, "Score function based on concentration degree for probabilistic linguistic term sets: an application to TOPSIS and VIKOR," Information Sciences, vol. 551, pp. 270-290, 2021.

[15] B. A. Addae, L. Zhang, P. Zhou, and F. Wang, "Analyzing barriers of smart energy city in accra with two-step fuzzy DEMATEL," Cities, vol. 89, pp. 218-227, 2019.

[16] L. Cui, H. K. Chan, Y. Zhou, J. Dai, and J. J. Lim, "Exploring critical factors of green business failure based on Grey-Decision Making Trial and Evaluation Laboratory (DEMATEL)," Journal of Business Research, vol. 98, pp. 450-461, 2019.

[17] F. Zhou, X. Wang, M. K. Lim, Y. He, and L. Li, "Sustainable recycling partner selection using fuzzy DEMATEL-AEWFVIKOR: a case study in small-and-medium enterprises (SMEs)," Journal of Cleaner Production, vol. 196, pp. 489-504, 2018.

[18] P. Li, J. Liu, and C. Wei, "Factor relation analysis for sustainable recycling partner evaluation using probabilistic linguistic DEMATEL," Fuzzy Optimization and Decision Making, vol. 19, no. 4, pp. 471-497, 2020b.

[19] K.-P. Lin, M.-L. Tseng, and P.-F. Pai, "Sustainable supply chain management using approximate fuzzy DEMATEL method," Resources, Conservation and Recycling, vol. 128, pp. 134-142, 2018.

[20] D. Wei, H. Liu, and K. Shi, "What are the key barriers for the further development of shale gas in China? A grey-DEMATEL approach," Energy Reports, vol. 5, pp. 298-304, 2019.

[21] L. J. Aaldering, J. Leker, and C. H. Song, "Analyzing the impact of industry sectors on the composition of business ecosystem: a combined approach using ARM and DEMATEL," Expert Systems with Applications, vol. 100, pp. 17-29, 2018.

[22] Y.-M. Wang, K.-S. Chin, G. K. K. Poon, and J.-B. Yang, "Risk evaluation in failure mode and effects analysis using fuzzy weighted geometric mean," Expert Systems with Applications, vol. 36, no. 2, pp. 1195-1207, 2009.

[23] V. Torra, "The weighted OWA operator," International Journal of Intelligent Systems, vol. 12, no. 2, pp. 153-166, 1997.

[24] Y. M. Wang and C. Parkan, "A minimax disparity approach for obtaining OWA operator weights," Information Sciences, vol. 175, no. 1-2, pp. 20-29, 2005.

[25] H. Liu and R. M. Rodríguez, "A fuzzy envelope for hesitant fuzzy linguistic term set and its application to multicriteria decision making," Information Sciences, vol. 258, pp. 220-238, 2014.

[26] J. Shieh, H. Wu, and K. Huang, "A DEMATEL method in identifying key success factors of hospital service quality," Knowledge-Based Systems, vol. 3, no. 3, pp. 220-238, 2010.

[27] W. Song and J. Cao, "A rough DEMATEL-based approach for evaluating interaction between requirements of product- 
service system," Computers \& Industrial Engineering, vol. 110, pp. 277-282, 2017.

[28] N. A. V. Doan and Y. De Smet, "An alternative weight sensitivity analysis for PROMETHEE II rankings,” Omega, vol. 80, pp. 166-174, 2018.

[29] B. Mareschal, "Weight stability intervals in multicriteria decision aid," European Journal of Operational Research, vol. 33, no. 1, pp. 54-64, 1988.

[30] P. Li and N. Wang, "A novel multi-period two-sided matching method on solving long-term care problem for disabled elders with probabilistic linguistic information," IEEE Access, vol. 8, pp. 149497-149509, 2020.

[31] M. Lin, H. Wang, Z. Xu, Z. Yao, and J. Huang, "Clustering algorithms based on correlation coefficients for probabilistic linguistic term sets," International Journal of Intelligent Systems, vol. 33, no. 12, pp. 2402-2424, 2018. 